\title{
The use of a publishing platform to facilitate the adaptation and development of Open Textbooks: A pilot report
}

\author{
Kate Nixon and Katya Henry
}

Queensland University of Technology

\begin{abstract}
After a successful proof of concept to expand the university's commitment to Open Educational Resources (OER), a pilot program was launched to facilitate the adaptation and development of Open Textbooks by academic staff for students as well as broader audiences. The pilot involved the use of the publishing platform Pressbooks as a mechanism to raise awareness of Open Educational Resources, and to provide a university-supported tool with which to develop Open Textbooks. Commencing in Semester 2, 2020, participants in the pilot received vendor training from Pressbooks, as well as support from learning and teaching and library staff. Pilot participants used the Pressbooks platform in a number of ways. Academics created textbooks as course material in a single unit, academics adapted open textbooks for Australian contexts over a number of units, and academics created open textbooks based on their research and not for a specific unit of study. Of the 13 pilot participants, five open textbooks were created, with one still in development. Responses to the pilot were mixed. Student feedback on the use of Pressbooks indicates that they enjoyed the structured and easy-to-read course material. Other students expressed frustration with the higher workload expectations of consuming material online prior to participating in synchronous classes. Students appreciated the zero cost of engaging with an open textbook. Academic feedback was also mixed, with some appreciating the flexibility and engagement that they can achieve in Pressbooks. Others were discouraged by the amount of time spent on creating material for little perceived benefit. The majority of academic staff who developed a textbook using Pressbooks would like to continue to use the platform.
\end{abstract}

Keywords: OER, Open Educational Resources, Open Textbooks, Equity, open access, Pressbooks

\section{Introduction}

Following a successful proof of concept which investigated the feasibility and practical potential for scaling up institutional support for OER, a university pilot scheme was launched. This pilot would support the adaptation and development of Open Textbooks by academics for the benefit of students as well as broader audiences. The Open Textbooks with Pressbooks Pilot involved the acquisition of the Pressbooks publishing platform, and participants received support from the university's Learning and Teaching Unit and from the Library to develop open textbooks. Participating staff used the Pressbooks platform in a number of ways: adapting existing textbooks; creating textbooks for specific units; and developing texts as research outputs for wider audiences. Students and staff who took part in the pilot had mixed responses to the platform and experience.

In this report we cover the aims and outcomes of the initial proof of concept and describe the goals and approach of the pilot project. We describe how we evaluated the pilot, what we discovered, and what we learned from the pilot participants.

\section{Background}

Open Educational Resources (OER), including open textbooks, are defined as free and openly licensed educational materials that can be used for teaching, learning, research, and other purposes (Creative Commons, 2016).

Benefits of OER include increased access to teaching and learning resources, enhanced access to learning, and improved student learning outcomes. Studies suggest that the use of open textbooks not only lead to higher student retention, better marks and greater literacy, but also reduce costs for students and thereby increase social equity for students (Feldstein, et. al., 2012; Hilton, 2016; Nussbaum, Cuttler, \& Swindell, 2020). 
The adoption of open textbooks in North American academic institutions is reaching maturity (Pitt, 2015; Bliss \& Smith, 2017). The UNESCO Recommendation on OER, unanimously adopted at the General Conference in 2019, supports the creation, use, and adaptation of OER, and facilitates international cooperation. It is the first international standard-setting instrument on OER (UNESCO, 2019). The 2021 Educause Horizon Report | Teaching and Learning Edition (Educause, 2021) named Open Educational Resources as one of six key technologies and practices that will have a significant impact on higher education teaching and learning.

Momentum is also growing in Australian institutions to adopt, adapt, and create open textbooks. QULOC (Queensland University Libraries Office of Cooperation) recently became the first Australian-based consortium to join the Open Textbook Network (OTN), a group of universities working to advance open textbook initiatives. The Council of Australian University Librarians (CAUL) has named Open Educational Resources as one of its strategic priorities under the umbrella of ‘Enabling a Modern Curriculum' (CAUL, 2020).

At our own institution, Open Educational Resources and open textbooks had already been in use in a small number of units. These resources had been adopted or adapted from already published open textbooks or had been written by academics with an interest in openly-licensed resources. An OER policy was created in 2016 to support the development of these resources. However, a 2018 Library OER Roundtable held with academics using OER in their units identified the need for additional support in order to increase the uptake in OER around the university.

The impetus to develop this additional support was prompted by the 2018 visit from OER advocate and practitioner, Dr Rajiv Jhangiani from Kwantlen Polytechnic University, Canada. This was followed by attendance at the 2019 QULOC Open Textbook Summer Institute facilitated by David Ernst from the Open Textbook Network (Open Education Network) and enriched by participation in the ASCILITE Open Educational Practice Special Interest Group.

\section{Proof of Concept}

An initial program was designed to support academics in identifying suitable units in which to adopt, adapt and create open textbooks. A proof of concept to include and create open textbooks in a small number of units would provide data to assess the feasibility and practical potential for scaling up support for OER in the future.

The Library and Learning and Teaching Unit were natural choices for assessing the nature and extent of support required to increase the use of open textbooks in courses. The Library would support staff to find suitable resources; and the Learning and Teaching Unit would provide technical and platform support, as well as strategic consideration and enhancement. The scope of the proof of concept is defined below:

1. Academics will include an open textbook in their unit by

a. Adopting of an existing open textbook: use, as is

b. Adapting an open textbook: some degree of modification e.g., localisation; or

c. Creating a new open textbook

2. Academics will be supported by Library and learning and teaching partners.

Scope of support: Library

- Find suitable open educational resources and open textbooks

- Support curation, publishing and access to chosen open textbooks

- $\quad$ Provide copyright and licensing advice

Scope of support: Digital Learning Portfolio

- Provide technical solutions and platform support including PoC publishing platform

- Provide strategic consideration and enhancement of the PoC.

\section{Outcomes and impact of the 2019 Proof of Concept}

The proof of concept was deemed a success. It demonstrated that investing in OERs would provide benefits for staff, the institution, and students. These benefits include enhanced relationships with participants, supporting the pedagogical and economic needs of students, providing reputational and budget advantages to the university, and contributing to strategic priorities. A summary of the outcomes of the proof of concept can be found in Table 1 below. 
Table 1. Outcomes and Impact of the 2019 Proof of Concept

\begin{tabular}{ll}
\hline \multicolumn{1}{c}{ Outcome } & \multicolumn{1}{c}{ Evidence of impact (drawn from evaluation data/strategies) } \\
\hline $\begin{array}{l}\text { For staff: encouraging and enabling new ways } \\
\text { of thinking and working }\end{array}$ & $\begin{array}{l}\text { Developing relationships with co-writers, including cross-institutional } \\
\text { Open education practice } \\
\text { Ability to modify a book for specific cohorts }\end{array}$ \\
\hline For the institution: & $\begin{array}{l}\text { Social responsibility, providing access to educational resources to the } \\
\text { public } \\
\text { Supporting diverse cohorts including first in family } \\
\text { Reputational benefit, showcases the work of the institution to a wider } \\
\text { audience, } \\
\text { Innovation } \\
\text { Contributes to institutional strategic priorities }\end{array}$ \\
\hline $\begin{array}{l}\text { For enabling/supporting unit or course } \\
\text { curriculum: Investing in curriculum and }\end{array}$ & $\begin{array}{l}\text { Provides a new avenue to for students to co-create knowledge } \\
\text { learning transformation }\end{array}$ \\
\hline For relevant groups: & $\begin{array}{l}\text { Positive impact on the Library resource allocation budget } \\
\text { Contributes to the Library strategic priorities for digital dexterity }\end{array}$ \\
\hline Specific transdisciplinary benefits: & Provides an avenue for transdisciplinary collaboration \\
\hline
\end{tabular}

\section{Recommendations from the Proof of Concept}

Based on the outcomes of the proof of concept, the following recommendations were made:

- Develop support mechanisms for adopting, curating and creating open textbooks

- Enhance the discovery of open educational resources through the library's catalogue

- Strategic commitment to OER from the institution

- Update the institution's Open Educational Resources policy and guidelines

- OER awareness campaign and dissemination through a series of events and training, facilitated through the Library and the Digital Learning Portfolio

- Exploration of contribution to research output for academic progression and other academic recognition

- Procurement of Pressbooks platform and pilot planning.

Pressbooks was selected as the publishing platform with which to launch the pilot. It was the recommended platform from colleagues within the OER field. Pressbooks is a global market leader in the specialised publishing eco-system of open education resources publishing. The eco-system incorporates the creation, cloning and distribution of open textbooks around the world. It is open source and integrates open-source plugins such as H5P interactive content, providing a greater learning experience for student participants. The platform is accessibility compliant and supports multiple publishing formats.

\section{Open Textbook Pilot}

After the successful proof of concept and acquisition of the Pressbooks publishing platform, the institution adopted a pilot program with the aim of expanding the facilitation of the adoption, adaptation, and creation of open textbooks by academics for our students as well as for broader audiences. The Open Textbooks with Pressbooks Pilot was launched in Semester 2, 2020.

\section{What did we want to achieve?}

The aim of the Open Textbooks with Pressbooks Pilot was to understand if the Pressbooks publishing platform supported the adoption, adaptation and creation of open textbooks for positive academic and student outcomes. 
The proposed outputs and deliverables from the pilot were as follows:

- A platform for the delivery of Open Educational Resources

- Open Educational Resources developed by staff

- Service model and vision to support open textbook use and creation in the institution

- Findings to be shared with academic executive to determine a move to institutional adoption

- Redevelopment of the institution policy and guidelines for Open Educational Resources

- Case studies and dissemination of outcomes to internal and external audiences

\section{How did we go about it?}

The approach taken with the Open Textbooks with Pressbooks Pilot was multi-faceted, and was comprised of four components:

1. Identification of staff participants, and enabling use of Pressbooks

2. Staff participant activities will include:

a. Adoption of an existing open textbook: use, as is

b. Adaptation of an existing open textbook: use, with some degree of modification e.g., localisation

c. Creation of a new open textbook

3. The Library will support participants by

a. Identifying suitable open textbooks

b. Supporting participants in publishing work/s as required.

c. Provision of licence support

\section{Evaluation}

Academic participants in the pilot were selected through an Expression of Interest process. Vendor training in the use of the Pressbooks platform was provided to selected unit coordinators. Academic staff were given access to a centralised Pressbooks account to create open textbooks.

The pilot supported academics in identifying units in which to adopt, adapt and create open textbooks, with Library support to find suitable resources; and Learning and Teaching support for technical and platform assistance, as well as assistance with strategic consideration and enhancement. The vendor also provided direct assistance to staff to create textbooks with the Pressbooks platform.

The Library also ran professional development sessions for library staff to increase awareness about the benefits of Open Educational Resources. A number of Library staff also completed the Creative Commons Certificate for Librarians, and together with the University Copyright Officer were able to provide expert advice on open licensing.

The evaluation of the pilot was undertaken at the conclusion of Semester 2, 2020, and recommendations were made to expand the pilot to adoption of Pressbooks for the development of open textbooks at the institution.

\section{Who took part?}

Of the thirteen original academic pilot participants, five open textbooks have been created, with two still in development. Six academic staff trialed Pressbooks to publish their content but did not continue with its use, citing reasons such as difficulty completing during an unexpectedly demanding year and the platform not being appropriate to display certain content types (i.e. LaTeX). The desired uses for incomplete books were academics creating open textbooks based on their research and not for a specific unit of study, academics developing original content for reuse across multiple courses, and academic staff adapting open textbooks for specific contexts.

Of the five open textbooks that were completed and deployed with students as course material in Semester 2, 2020, there were three different ways the open textbooks were used: an academic creating original textbooks as course material in a single unit; academics adapting open textbooks for Australian contexts over a number of 
units; and an academic adapting an option textbook for an individual unit. The evaluation focussed on the completed and deployed textbooks.

\section{How did we evaluate it?}

The pilot sought to answer a number of key questions:

- What students are using the platform and how were they using it?

- What staff were using the platform and how were they using it?

- How did students perceive the usefulness of the platform?

- How do staff perceive the usefulness of the platform?

- Was the platform effective for students?

- Was the platform effective for staff?

- Did the platform represent value for money?

Academic staff gave feedback on the platform in the form of a one-hour structured interview undertaken in the final weeks of the semester. Interviews were recorded and responses were analysed to understand key themes in their responses.

Table 2. Academic Interview Questions

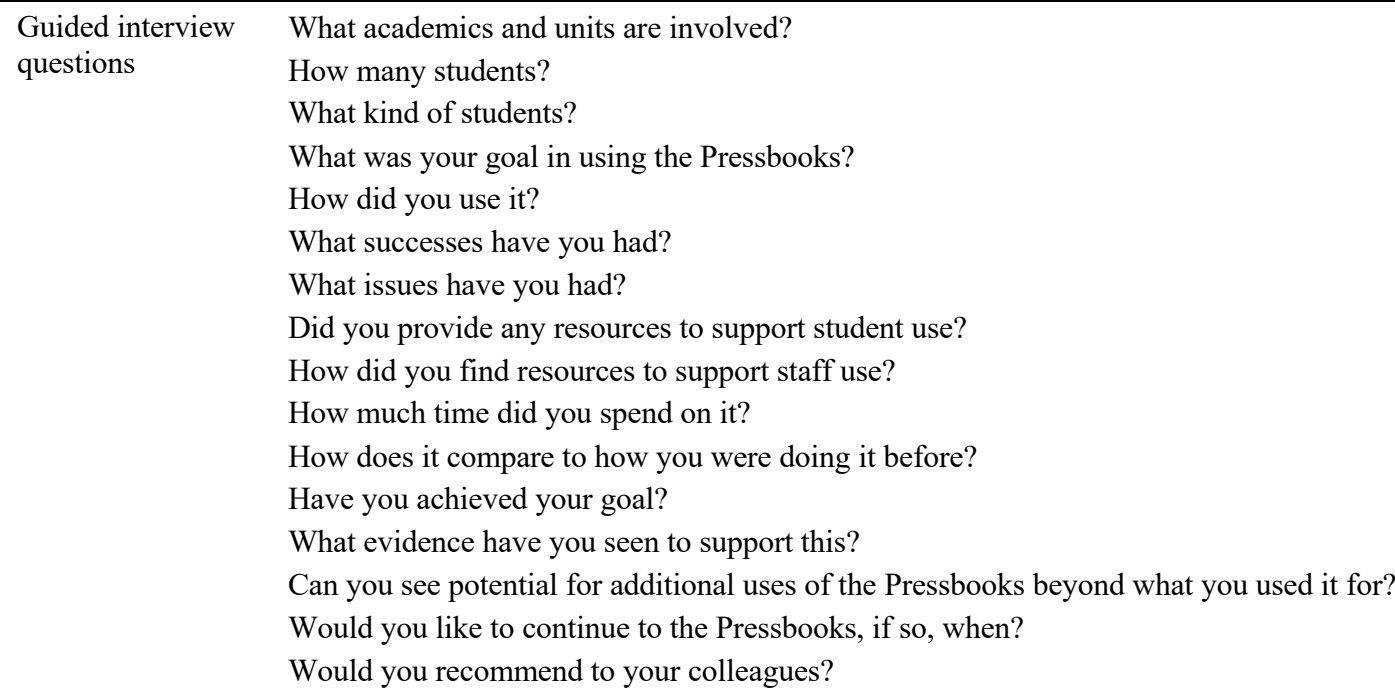

Students' opinions of the pilot were gathered in a short, anonymous and optional online survey [Table 3].

Table 3. Student Survey Questions

\begin{tabular}{ll}
\hline Likert scale & I usually read the online textbook before my workshop. \\
questions & I found accessing my online textbook easy \\
& I found my online textbook user-friendly and easy to navigate \\
& I found the content of my online textbook relevant to my study \\
& I found the interactive elements in my online textbook improved my learning \\
& I felt supported in using my online textbook \\
& I used my online textbook more frequently than textbooks in other units \\
& I found alternate formats (Mobi, ePub, PDF etc) of my online textbook helpful \\
& Textbook costs are a financial burden to me \\
& I prefer accessing my online textbook to textbooks in other units \\
\hline Multiple choice & How do you usually access your required textbooks \\
questions & I have used my textbook with which frequency \\
& I have used the following features of my online textbook
\end{tabular}




\begin{tabular}{ll}
\hline Open ended & What worked well about using online books instead of lectures? \\
questions & What did not work well about using online books instead of lectures? \\
& What worked well about the workshops in these weeks? \\
& What did not work well about the workshops in these weeks? \\
& What changes would you suggest? \\
\hline
\end{tabular}

To supplement the feedback from pilot participants, the data from Pressbooks and Google Analytics on views of deployed open textbooks were also interrogated.

\section{What did we discover?}

\section{From our academic partners?}

Academic staff feedback can be categorised into a number of themes, including ease of use, technical issues, student outcomes, and learning and teaching opportunities. Academics had a mixed response to how easy the platform was to develop content in. Some staff appreciated the vendor training and thought it gave them a good basis for using the platform. Others thought that no training was required, and the platform was straightforward and easy to operate. Conversely some staff thought that Pressbooks was 'finnicky' and took some time to become confident in its use. These responses did not correlate with whether or not an academic staff member thought of themselves as 'tech savvy', instead whether or not they had used content authoring platforms such as WordPress previously. Some academic staff received significant help from Learning Design and Learning Technologist staff, whereas some developed books with no learning and teaching support.

There were some technical issues that were reported when using the platform, including glitches when loading multiple videos in a chapter where subsequent videos would not display. There was also an issue with images embedded using the book images library being low resolution, particularly when details of the images needed to be seen clearly by students. Another issue was found when H5P activities would not clone across multiple editions of a book with multiple authors. Some academics felt buffered from technical issues through the support of learning and teaching staff.

Academic staff indicated they felt that using Pressbooks helped them to better structure and present their content in ways that would make sense for their context, using existing styles and formats in a structured chapter format rather than if they were using a learning management system. Some staff appreciated the flexibility they were able to achieve embedding videos, images and activities in Pressbooks. They felt the contextual activities would lead to better student engagement with the content and saw this demonstrated with end of chapter quiz results. Conversely, other academics were frustrated by the amount of time spent on creating material for little perceived benefit, when compared with a traditional lecture format with academic readings delivered through the Library platform in the LMS. The majority of academic staff who have developed a textbook using Pressbooks would like to continue using the platform.

\section{From our students?}

A total of 188 students responded to their end of unit online survey across five units that deployed a Pressbooks textbook in class. $59 \%(n=89)$ of students were in the age range of $17-22$, indicating these students were primarily undergraduates and school leavers.

Just $42 \%(n=79)$ of students indicated that they would usually purchase their recommended or required textbooks either new from the bookshop, or second hand, with $34 \%(n=63)$ indicating they would usually borrow from the university library or share their textbook with a friend. $25 \%(n=46)$ of students indicated they would not usually access or purchase their required or recommended textbook. 
Figure 1. Age range of student respondents

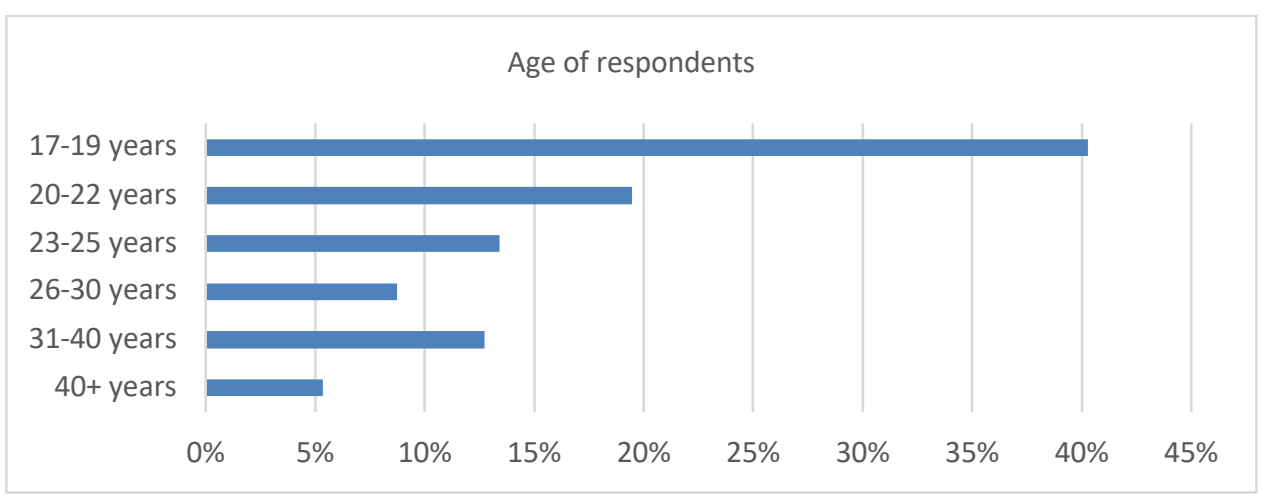

Figure 2. Student responses: How do you usually access your required or recommended textbooks?

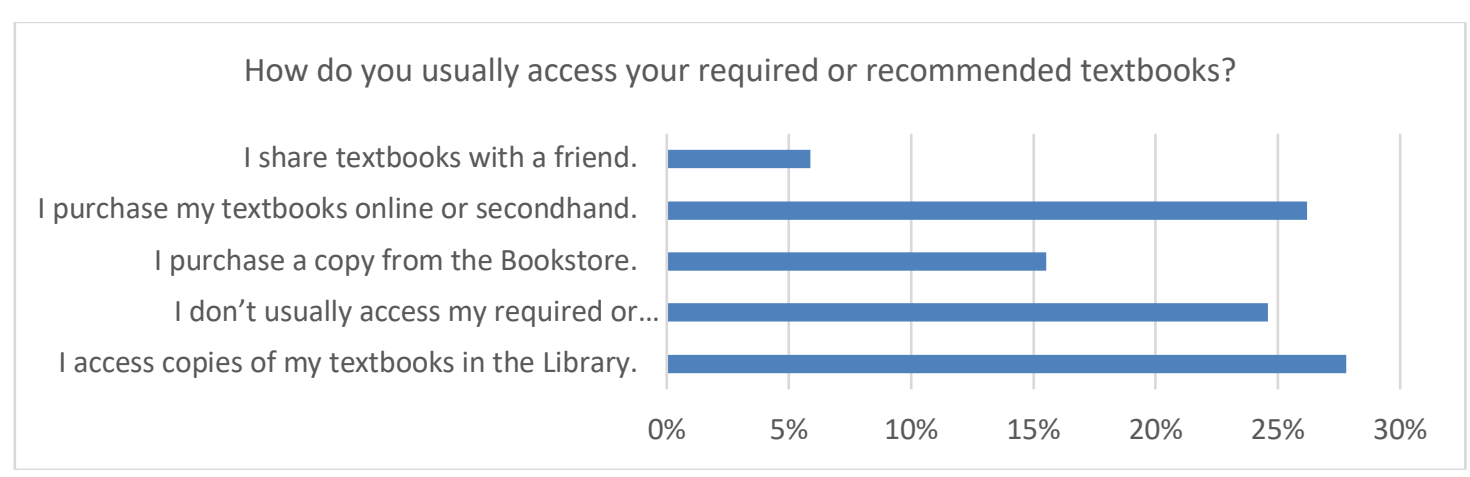

A Google Analytics layer was applied to released Pressbooks textbooks that indicated a total of 17,071 page views on the five books over the duration of Semester 2 in five units of study. With an average overall session of 05:37, peaking prior to assessment periods at 11:05. Total class enrolments for these units were 907 students. $74 \%(\mathrm{n}=137)$ of students self-reported that they used their Pressbooks text more frequently than every 2 weeks, with only $2 \%(n=3)$ saying they did not open their textbook.

\section{Figure 3. Student responses: I have used my Pressbooks with which frequency?}

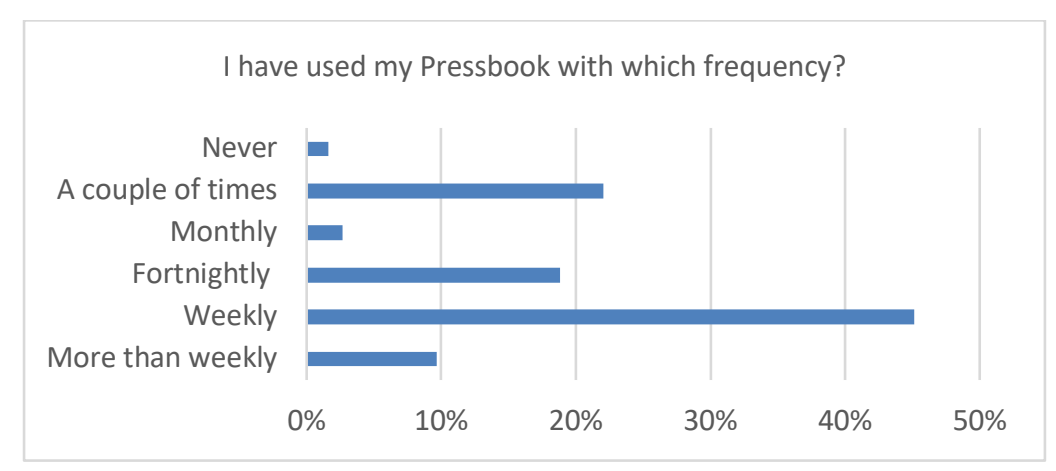

Of student respondents, only $79 \%(n=149)$ indicated that they had read their assigned readings. $48 \%(n=89)$ watched videos that were presented in their online textbook, $46 \%(n=87)$ completed the activities that were developed in the textbooks. Some features that were not part of prescribed activities for students were also used, including $17 \%(\mathrm{n}=32)$ annotating sections of their textbook, $4 \%(\mathrm{n}=7)$ printing a copy of their text, and $8 \%$ (15 students) converting their textbook to an alternate format.

Students overwhelmingly reported that accessing their textbook was easy ( $95 \%$ positive or neutral), and that they found the book user friendly and easy to navigate (91\% positive or neutral). $86 \%$ of student respondents were positive or neutral towards the relevance of their textbook content to their study. $65 \%(\mathrm{n}=122)$ students 
also reported that the textbook was relevant to their study, and $54 \%(\mathrm{n}=92)$ agreed that the interactive elements improved their learning. 55\% $(\mathrm{n}=155)$ students indicated that textbook costs were a financial burden to them. Students were largely neutral on if they used their online textbook more frequently than in other units, and if they preferred their Pressbook to textbooks in other units.

Figure 4. Student responses: I have used the following features of my Pressbook

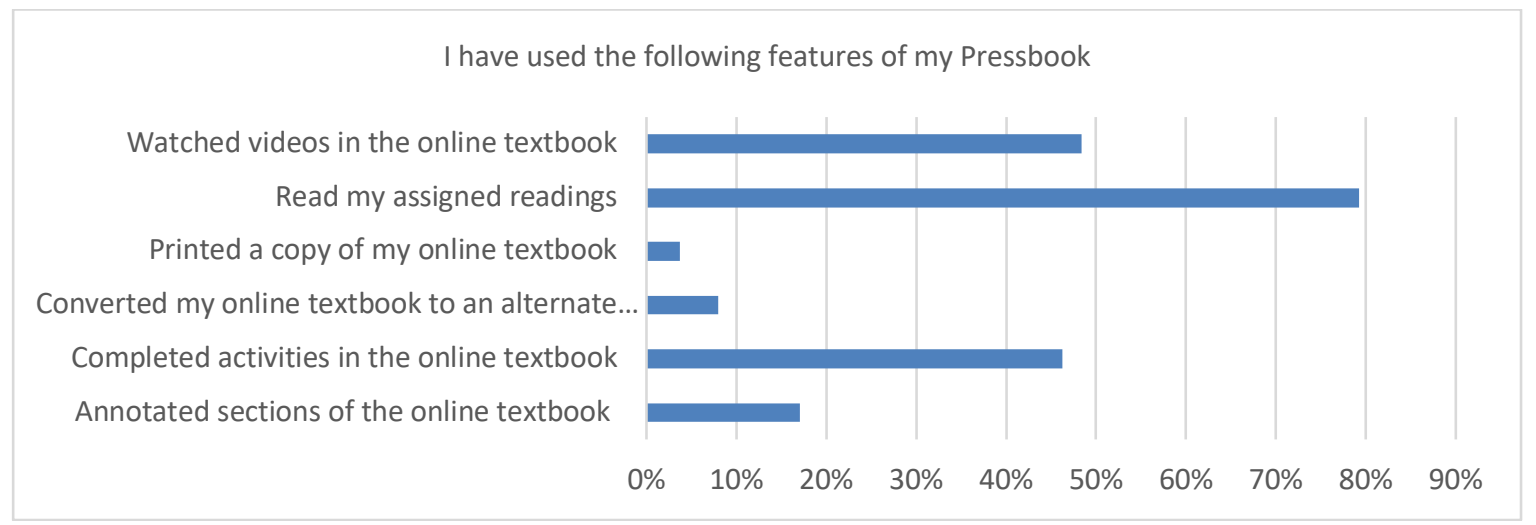

Figure 5. Student responses: Likert scale questions

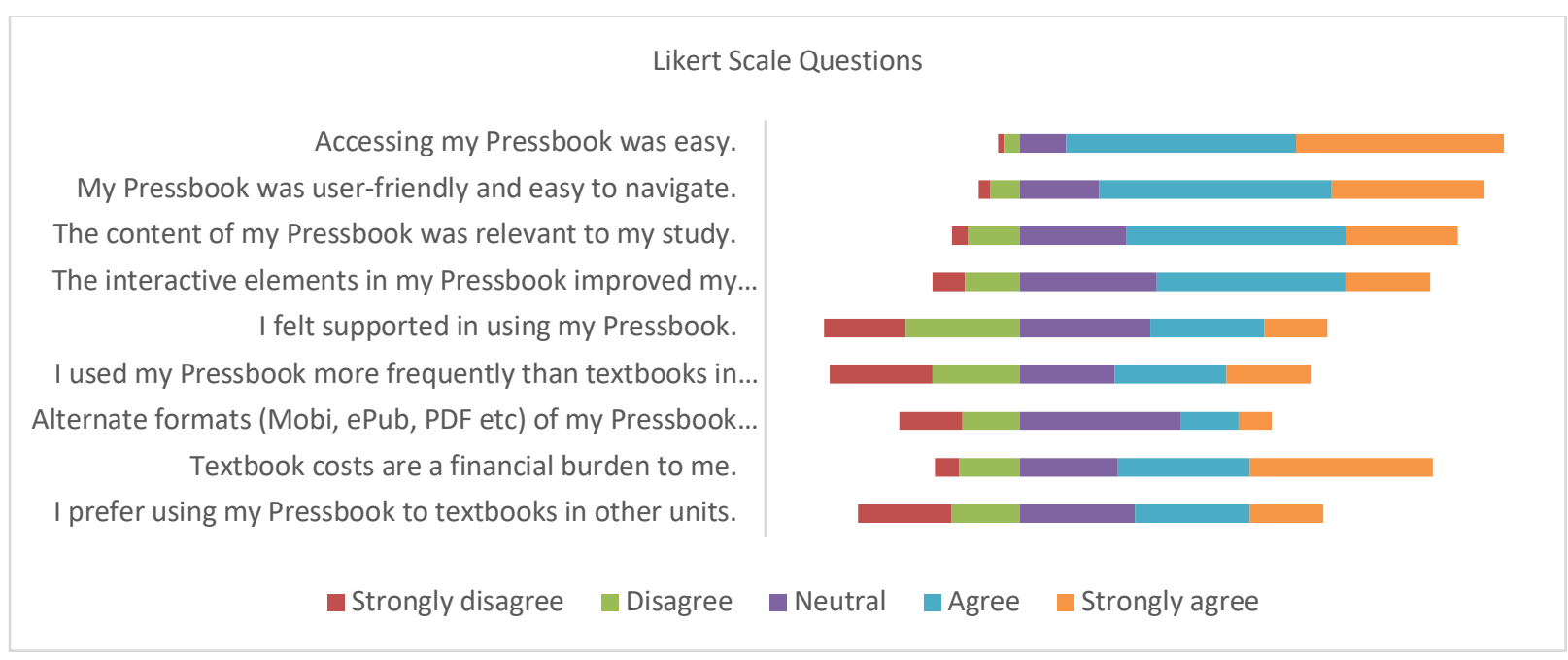

Student qualitative feedback varied dependent on the way the Pressbook was developed and integrated into the class. In the unit where the book was an original work, student feedback was overwhelmingly positive, and can be grouped into the following themes: engagement, relevance, workload, ease of use, impact on learning and access. Students found the online book very engaging, citing that they felt connected to the academic staff member as they read the book, in particular due to the more informal writing style and humour in the text. Students appreciated the direct relevance of the content to their study, but also noted that as the book was written specifically for their context that it could have been a little more directed, with less supporting material and only what was necessary to achieve the learning outcomes. With workload, some students indicated that the size of format of the textbook made the workload seem daunting. Students had some suggestions about additions to the book they thought might support their learning, including case studies and expected learning outcomes, they also appreciated interactive and engaging elements including H5P activities, videos and podcasts that helped to break up the heavy subject matter and gave opportunities to consolidate the learning. Overwhelmingly students also appreciated the ease of use of the online textbook and loved that it was free and easy to access.

In the four units that adapted an existing open textbook for their context feedback was themed into around workload, learning and ease of use. Students in this group found the workload to be considerably higher and often commented that they would prefer a traditional lecture. 


\section{What did we learn in the pilot?}

Students found the structured and organised nature of their open textbooks a positive experience, navigating books was easy with a clear and consistent format. Given the requirement for strict adherence to styles and format in the Pressbooks, and the pre-loaded templates available for selection, achieving a clearly structured artifact was easier for academics to deliver for students in comparison to developing content within a document or an LMS platform. One group in the pilot used a custom template that took a significant amount of time to develop, however there was no indication in student feedback that this custom template was found more useful than the existing templates used in other Pressbooks.

The majority of students were ambivalent about the availability of alternative formats for their Pressbooks textbook. However, on interrogation of the qualitative feedback, students that had reported positive responses for alternate formats further qualified with reasons why they enjoyed them. These included being able to engage with their textbook on a mobile device while doing another activity, i.e. in transit or with family. Some books did not have alternate formats available for students, which indicates that academics need to be informed about this option in the settings. While the pilot cohort did not have any students self-identify as being on an access equity plan, the institution is working towards more accessible content in support of students who might have difficulty engaging with traditional forms of content.

From the evaluation data, $25 \%$ of students did not usually access their required or recommended textbooks at all, contrasting with only $2 \%$ of students from the same cohort who indicated they had not accessed their Pressbooks textbook, which would indicate a far higher level of student engagement with their academic reading materials. Interestingly, students did not significantly preference using a Pressbooks textbook more than using a traditional textbook and self-reported that they did not use their Pressbooks textbook more than a traditional textbook. There were however positive comments on the zero cost book and the impact it had on personal finances.

As the prescribed textbooks were intentional in their relevance to the course content, students found it was more work to engage with the book than it often was with other textbooks. While expressing a dislike for the additional perceived workload, students still acknowledged that this workload was beneficial to their learning and helped them connect with their coursework. It also helped them to be more prepared for class. The perceived additional workload made up the majority of negative qualitative feedback from students and aligns with research on students' perceptions of workload in other flipped classroom approaches (van Alten, Phielix, Janssen, \& Kester, 2019, p. 12). The pilot took place during 2020, and these results must be considered in line with the significant upheaval and change to classroom teaching due to COVID-19 lockdowns that students experienced during this time.

There was a difference in the student reception of some Pressbooks books comparative to others, which reflects differences in the intent, the learning model and the delivery of the content to students. When the learning was designed specifically to incorporate a Pressbook as the primary source of academic reading, supported by synchronous sessions to consolidate the learning, students felt more engaged and positive about the experience. Situations where the textbook was not treated as a core component of the learning in synchronous sessions had less success with student satisfaction. There was also a significant difference in time spent, or the perception of value of the time spend by academics in the pilot, in line with this finding.

Table 4. Outcomes and Impact

\begin{tabular}{ll}
\hline \multicolumn{1}{c}{ Outcome } & \multicolumn{1}{c}{ Evidence of impact (drawn from evaluation data/strategies) } \\
\hline For students: & $\begin{array}{l}\text { Students are engaging with online textbooks } \\
\text { Students enjoyed the level of detail and ability to engage with course materials at their own } \\
\text { pace } \\
\text { Students found contextualised resources relevant to their study } \\
\text { Students found interactive elements improved their learning }\end{array}$ \\
\hline For staff: & $\begin{array}{l}\text { Pressbooks provides a new way to publish learning and teaching materials, with } 43 \\
\text { Professional staff with accounts in the platform } \\
\text { New capability to publish OER, five published books and two in development } \\
\text { Academic feedback indicates an easy to develop and 'slick' looking final product. }\end{array}$ \\
\hline
\end{tabular}




\begin{tabular}{ll}
\hline For the institution: & $\begin{array}{l}\text { Advancement in OER capability. With OER resources developed by staff and workshops } \\
\text { for staff to understand the benefits of OER for students. }\end{array}$ \\
\hline $\begin{array}{l}\text { For enabling/supporting } \\
\text { unit or course curriculum: }\end{array}$ & $\begin{array}{l}\text { Pressbooks enables a new way of contextualising Open Educational Resources for specific } \\
\text { learning and teaching contexts.Three textbooks have been adapted for specific learning and } \\
\text { teaching contexts. }\end{array}$ \\
\hline
\end{tabular}

\section{Conclusion and next steps}

In this report we provided an overview of a pilot designed to increase the use and creation of open educational resources. The Open Textbooks with Pressbooks Pilot was implemented following a successful proof of concept, which provided data on the feasibility and practical potential for scaling up support for Open Educational Resources.

The pilot involved the acquisition of the Pressbooks publishing platform, and participating unit coordinators were provided with vendor training in how to use the platform. Participants also received support from the Learning and Teaching Unit and the Library to identify suitable units in which to adopt, adapt, or develop their own textbooks. Participating staff used the Pressbooks platform in a number of ways: to adapt existing textbooks; to create textbooks for specific units; and to develop texts as research outputs for wider audiences.

Students and staff who took part in the pilot had mixed responses to the platform and experience. Student feedback indicated they enjoyed the structured and easy-to-read course material. Other students were frustrated with higher workload expectations of consuming material online prior to participating in synchronous classes. Students appreciated the zero cost of engaging with an open textbook. Academic feedback was also mixed, with some appreciating the flexibility and engagement that they can achieve in Pressbooks. Others were frustrated by the amount of time spent on creating material for little perceived benefit. Despite any criticisms, the majority of academic staff who developed a textbook using Pressbooks indicated that they would like to continue to use the platform.

As a result of the pilot's success, a number of recommendations were made. The university has extended its Pressbooks licence in order to progress its commitment to supporting the adoption, adaptation, and creation of OERs. A recommendation for the appropriate use of Pressbooks was made, with an emphasis on using the platform as a mechanism to develop and distribute Open Textbooks, and not to use the platform to create course materials that would be best suited to deployment in a Learning Management System. Capability in Library and Learning and Teaching Unit staff must also be developed in order to provide sustainable support to academics wishing to develop open textbooks using Pressbooks.

The university is formally committed to the creation and dissemination of knowledge for the benefit of society. This commitment includes supporting the use and dissemination of Open Educational Resources to widen access to education, and to improve the quality of teaching and learning outcomes (QUT, 2021). The Open Textbooks with Pressbooks Pilot and the implementation of its recommendations supports and enhances this commitment.

\section{References}

Bliss, T. J, and Smith, M. (2017). A Brief History of Open Educational Resources. In: R. S. Jhangiani and R. Biswas-Diener (Eds.), Open: The Philosophy and Practices that are Revolutionizing Education and Science (pp. 9-27). London: Ubiquity Press. https://doi.org/10.5334/bbc.b. CC-BY 4.0

Council of Australian University Librarians. (2020). Strategy. https://www.caul.edu.au/about-caul/strategy

Creative Commons. (2016). What is OER? https://wiki.creativecommons.org/wiki/What_is_OER\%3F.

Educause. (2021). 2021 Educause Horizon Report | Teaching and Learning Edition. https://ibrary.educause.edu/resources/2021/4/2021-educause-horizon-report-teaching-and-learning-edition

Feldstein, A., Martin, M., Hudson, A., Warren, K., Hilton, J., \& Wiley, D. (2012). Open textbooks and increased student access and outcomes. European Journal of Open, Distance and E-Learning.

Hilton, J. (2016). Open educational resources and college textbook choices: a review of research on efficacy and perceptions. Education Tech Research Dev 64, 573-590. https://doi.org/10.1007/s11423-016-9434-9

Nussbaum, A. T., Cuttler, C., \& Swindell, S. (2020). Open Educational Resources as a Tool for Educational Equity: Evidence from an Introductory Psychology Class. Frontiers in Education, 4(152).

10.3389/feduc. 2019.00152 
Pitt, R. (2015). Mainstreaming of open textbooks: Educator perspectives on the impact of OpenStax College Open Textbooks. International Review of Research in Open and Distributed Learning, 16(4), 133155. 10.19173/irrodl.v16i4.2381

Queensland University of Technology. (2021). Manual of Policies and Procedures C/7.2 Open Educational Resources. https://www.mopp.qut.edu.au/C/C_07_02.jsp

van Alten, D.C.D., Phielix, C., Janssen, J., \& Kester, L. (2019). Effects of flipping the classroom on learning outcomes and satisfaction: A meta-analysis. Educational Research Review, 28.

https://doi.org/10.1016/j.edurev.2019.05.003

Nixon, K. and Henry, K. (2021). The use of a publishing platform to facilitate the adaptation and development of Open Textbooks: A Pilot Report. In Gregory, S., Warburton, S., \& Schier, M. (Eds.), Back to the FutureASCILITE '21. Proceedings ASCILITE 2021 in Armidale (pp. 352-362). DOI:

https://doi.org/10.14742/ascilite2021.0151

Note: All published papers are refereed, having undergone a double-blind peer-review process.

The author(s) assign a Creative Commons by attribution licence enabling others to distribute, remix, tweak, and build upon their work, even commercially, as long as credit is given to the author(s) for the original creation.

(C) Nixon, K., Henry, K. 2021 